vance of potassium to this form of hypertension.

\section{Ethics of Research and the Developing Countries}

The patient, a man of 44 with one remaining kidney (right nephrectomy 15 years ago for lithiasis), has been under our care since 1967 with severe hypertension and a raised blood urea. Despite conservative treatment he became semistuporous in November 1968. His blood urea was then 200-300 mg./100 ml., and creatinine clearance 2-4 $\mathrm{ml}$./minute. An arteriovenous fistula was established and the patient was put on twice weekly haemodialysis with a R.S.P. Travenol artificial kidney, using Uhra Flo 100 or E X-01 dialysers at a blood flow rate $200-300 \mathrm{ml}$./minute for sixeight hours. The dialysate concentration consisted of $\mathrm{Na} 132$, acetate $35, \mathrm{Cl} 102$, $\mathrm{Ca} 3, \mathrm{Mg} 0.8$, and $\mathrm{K} 2.5 \mathrm{mEq} / 1$. His diet contained $50 \mathrm{~g}$. protein, $15-20 \mathrm{mEq}$ of potassium and $70-75 \mathrm{mEq}$ of sodium. He also received $500 \mathrm{mg}$. of methyldopa daily. Immediately after starting haemodialysis the secretion of urine stopped completely. The patient's general condition improved. The haematocrit increased spontaneously from 22 to $30 \%$ without any transfusion, and the blood urea was between 60 and 150 mg./100 ml. However, daily blood pressure was consistently high : 180-240/110-140 during the first ten months of treatment. He had papilloedema, haemorrhages, and exudates in both fundi.

A potassium-free dialysate was then instituted. The diet was unaltered, but the potassium intake augmented from $15-20$ to 70-80 mEq. His blood pressure, systolic and diastolic, gradually responded to antihypertensive treatment, and for six months remained around normal limits. It is now stabilized at 140-170/90-105 without any medication. The fundal lesions have also completely disappeared. The patient presented no symptoms or signs of hypokalaemia, with a serum potassium from 2.25 to $5.75 \mathrm{mEq} / \mathrm{l}$. between two successive haemodialyses.

This patient was treated for nearly a year with a dialysate containing $2.5 \mathrm{mEq} / 1$. of potassium and remained hypertensive. The additional repeated depletion of potassium of $250-300 \mathrm{mEq}$ twice weekly caused the high blood pressure to fall gradually, and the ocular lesions to regress. This observation is in accordance with experimental and clinical data indicating that a potassiumdeficient state is characterized by a decrease of vascular reactivity to certain stimuli, especially to the renin-angiotensin system, and may lower high blood pressure in rats with renovascular hypertension. ${ }^{1-4}-\mathrm{We}$ are, etc.

H. YATZIDIS.

\section{TRIantafillidis}

S. Voudiclaris.

C. Koutsoyannis.

General Clinic of Athens,
Athens, Greece.

REFERENCES

Friedman, M., Rosenman, R. H., and Freed, S. C. American fournal of Physiology, 1951, 167, 457. Tobian, L., Physiological Reviews, 1960, 40, 280. Investigation, 1967, 16, 539 .

4 Zech, P., Sassard, J., Moskovtchenko, J. F., Pozet N., and Traeger, J., in Dialysis and Renal Transplantation: Proceedings of the 5th Conference of the European Dialysis and Trans Amsterdam, Excerpta Medica, 1969.
SIR,-While agreeing with some of the sentiments expressed by Professor B. Ringelhann (12 September, p. 643) I feel that he presents a rather one-sided picture concerning collaborative studies undertaken partly in the developing and partly in the developed countries.

Anyone who has worked in the developing countries would know, as even Professor Ringelhann admits, that facilities for many investigations are not available, and that some studies can only be undertaken in collaboration with colleagues in the developed countries. It would be sad to conclude that these studies should not be undertaken, especially as often ideas as well as blood samples emanate from the developing countries. Naturally, these studies have to be truly collaborative, and if facilities and staff are available the greater part should be undertaken on the spot.

These collaborative studies, apart from their scientific value, often bring not only the individuals affected but whole departments closer together, and in fact lead to the goal for which Professor Ringelhann is striving. - I am, etc.,

\section{Department of Pathology, \\ Rotterdam, Holland.}

\section{A. Talerman}

\section{Wrong Operations}

SIR,-Mr. T. K. Lyle (19 September, p. 711) rightly adumbrates various safeguards against the disaster of operating on the wrong area; name bracelets and indelible pencil marking are mooted, and no doubt other measures are in vogue. But most cogent of all in Mr. Lyle's commentary is the fact that a responsibility lies with the surgeon personally to examine the patient. I would go further than Mr. Lyle, however, in his maintaining that this obligation is necessary for deciding what operation is to be undertaken and other purely technical desiderata.

In my credo this personal, preoperative contact is imperative because the patient is a human being and not a computerized symbol. He has feelings, is under stress and full of anxieties, and these will in no way be allayed on a trolley journey into a totally impersonal, imponderable anaesthetic-laden ambience.

"Sustained and soothed by an unfaltering trust . . . lies down to pleasant dreams", as the American poet, William Cullen Bryant, has it, will be the inestimably more desirable state of composure when the man conscience evokes his innate kindliness as well as the use of his capable surgeons' hands. - I am, etc.,

Grimsby, Lincs.

\section{Living it up with Concorde}

SIR,-Your interesting leading article (19 September, p. 661) surveys some physical factors of importance to supersonic travel but does not afford much space to the physiological aspects of such flights.

Of special interest in that direction is the nevitable disturbance of diurnal (or solar) rhythm. This affects passengers and crew alike, and stems from the crossing of time zones at high velocity. Such a phenomenon is familiar to present-day long-distance jet commuters, flying to East or West. The same journeys, made at twice the speed of sound, promise to be even more traumatic to the control of bodily rhythm. Clinically it is well recognized that after such a flight the passenger may require a week or longer to adapt to the solar time rhythm of his new environment. During this period of adaptation he may suffer disturbances of sleep rhythm, lethargy, mental sluggishness, and even frank depression of mood. Biochemically there is change from the normal ebb and flow of water and electrolytes. This disturbance has been said to arise from conflict between man's intrinsic circadian rhythm and normal solar rhythm, the latter being "put out of joint" temporarily by the abrupt exchange of one solar time for another.

Future Concorde travellers may find this effect greatly magnified, especially if crossings are undertaken frequently, as is inevitable for aircrews. The resulting loss of efficiency could have serious consequences on safety in the air.-I am, etc.,

Klaus HeymanN.

London W.11

\section{Recovery from Overdose with Glibenclamide}

SIR,-Experimental evidence with glibenclamide, a sulphonylurea recently put on the market which is effective in the management of diabetes, suggests that it has a different mechanism of action from other sulphonylureas, giving slower and more prolonged effects on blood glucose and insulin concentrations than tolbutamide. ${ }^{1}$ I should like to report a case of overdose with rapid and complete recovery.

A 15-year-old boy was admitted to casualty at 6.45 p.m. on 19 June deeply unconscious. No history was available at the time, but subsequently it was found out that during the evening he had smoked cannabis and taken an unknown number of Mandrax tablets. He had returned home with a hangover for which he had taken some aspirins and swallowed a number of his father's supply of $5 \mathrm{mg}$. glibenclamide tablets. The exact number is not known, but it was certainly not less than 20. At 4 a.m. his father found him apparently asleep, but when he appeared still to be asleep more than 13 hours later- 5.30 p.m.-he brought him into the casualty department.

On examination the boy was deeply unconscious and totally unresponsive to all stimuli. Blood pressure was $110 / 70$, pulse was 72 , with sinus arrhythmia.

An overdose of drugs was suspected, and after blood was taken for tests, an intravenous infusion of normal saline was set up. Laboratory investigations were all within normal limits except for the blood glucose which was $22 \mathrm{mg} . / 100 \mathrm{ml}$. Blood count was normal. On finding the marked hypoglycaemia, treatment was changed to intravenous dextrose and he was given 500 ml. normal saline, $1,000 \mathrm{ml}$. of $5 \%$ dextrose, and $120 \mathrm{ml}$. of $50 \%$ dextrose in one hour Two hours after admission he developed torsion spasm with prolonged cyanosis. Because of these attacks he was given two doses of $5 \mathrm{mg}$. diazepam intravenously. The spasm thereafter subsided. Nine and a half hours after admission he had recovered fully and his blood sugar was within normal limits. After three days he was allowed to 
go home, having no obvious sequelae. His liver function tests, electrolytes, and urea were repeated on the day of his discharge and all were normal.

Glibenclamide and its metabolites are more than $97 \%$ bonded by serum proteins. About $25 \%$ of radioactive glibenclamide is excreted in the faeces and the rest in the urine. In contrast to chlorpropamide, the hypoglycaemic reaction to glibencamide is not protracted and is easily controlled by a reduction of the dosage. It is interesting to note phenformin has no hypoglycaemic action in normal people, but this is obviously not so in glibenclamide.

This patient's recovery appeared to be fairly rapid and without any immediate damage to kidneys or liver as judged by crude tests of liver function, electrolytes, and urea.

I should like to thank Dr. Donald Kinloch for advice and for permission to report this case and Dr. Norman Peters for advice.-I am, etc.

\section{Chase Farm Hospital, \\ P. Kullavanijaya. \\ Enfield, Middx. \\ REFERENCE \\ 1 Loubatiéres, A.., Mariani, M., M., Ribes, G., de Malbosc.
$1969,5,1$.}

\section{Myocardial Infarction and the G.P.}

SiR,--One of us, a general practitioner, has felt increasing concern at the lack of specific treatment available on first attendance at a case of myocardial infarction. The use of anti-arrhythmic drugs is well established for inpatients and after hospital discharge, and there now seems a good case for their use ab initio by the general practitioner. A symposium attended by a group of eminent London cardiologists was recently held at this Centre, and there was unanimous agreement among them endorsing the value of both lignocaine and atropine as a "first-aid" treatment in selected cases. It was further agreed that the highest proportion of preventable deaths occurred in the first two hours and before admission to hospital.

A subsequent meeting was held here to discuss this matter in more detail, and the following programme of action was suggested for practitioners admitting cases to the coronary care unit:

(1) Injection of an appropriate analgesicintravenously if pain is severe or the patient shocked. This can be morphine $10 \mathrm{mg}$. or diamorphine $5 \mathrm{mg}$. The latter acts more quickly, and is perhaps slightly less emetic. (Intravenous pentazocine $30 \mathrm{mg}$. has been advocated as less depressing to the blood pressure. ${ }^{1}$ ) If hypotension develops, the patient should be kept flat, and the foot of the bed raised. This posture, if it can be tolerated, should be maintained during carriage into the ambulance and during the journey, but some patients in acute left ventricular failure may have to sit up.

(2) Bradycardia develops in about $10 \%$ of cases, and represents a threat of cardiac arrest. Intravenous atropine $0 \cdot 4-0.6 \mathrm{mg}$. should be given if the pulse rate falls below 60 . A total of $1.2 \mathrm{mg}$. may be used if necessary during the first three hours, and hypotension is no contraindication.

(3) It was felt that the use of intravenous lignocaine should be confined to those cases in which ectopic beats occur with a frequency of six or more per minute. Such ectopics represent a greater danger of ventricular fibrillation if they form runs of two or more, or if an E.C.G. shows them to be ventricular ectopics falling on the preceding ' $T$ waves.

The drug should be given slowly (over 1 to 2 minutes) either as $10 \mathrm{ml}$. of a $1 \%$ solution (100 mg.), or as $5 \mathrm{ml}$. of a $2 \%$ solution, in which form it has recently become available as a syringe pack. Care should be taken not to use the local anaesthetic preparation containing a small percentage of adrenalin. Once initiated, the dose should be repeated every 20 minutes, as it is rapidly broken down. Being a myocardial depressant, the blood pressure should be watched, but it is considered that the arrhythmia represents a greater threat than the hypotension. If the ambulance journey is likely to take longer than 20 minutes, 50 mg. should be given intravenously with an additional injection of $200 \mathrm{mg}$. intramuscularly. Lignocaine intramuscularly is more slowly absorbed and has been shown to produce effective blood concentrations for up to two hours." Care should be taken to ensure that the larger injection does not enter a vein.

It would seem clear that these cases in which there is a disturbance of rate or rhythm are the ones most urgently in need of monitoring in a unit, and that the use of these drugs by the general practitioner can help to get them there safely.-We are, etc.,

\section{C. Bousfield \\ J. N. MICKERSON. J. D. Whiteside. \\ Chichester Postgraduate Medical Centre, \\ St. R:chard's Hospital,
Chichester, Sussex. \\ REFERENCES \\ Scott and Orr, Lancet, 1969, 1. 1065 \\ Scott et al., Lancet, 1968, 2, 1209. \\ Low-oestrogen Oral Contraceptives}

SIR,-Dr. Ellen C. G. Grant's account (15 August, p. 402) of symptoms occurring in patients taking low-oestrogen oral contraceptives prompts us to write of our experience of a group of patients in our clinic.

Sixty patients who were taking part in a side-effects study of Ortho-Novin $2 \mathrm{mg}$. (norethisterone $2 \mathrm{mg}$. + mestranol 100 $\mu \mathrm{g}$.) were changed to Ortho-Novin $1 / 50$ (norethisterone $1 \mathrm{mg}$. + mestranol $50 \mu \mathrm{g}$.) following the warning by the Committee on Safety of Drugs on the dangers of highly oestrogenic oral contraceptives (25 April, p. 231). These women had taken the higher dosage for a total of 448 cycles and the following sequelae were noted after a total of 363 cycles on the low dose preparation. Almost half of the patients (29) noticed markedly reduced vaginal bleeding, of whom eight had complete pseudoamenorrhoea. Slight break-through bleeding occurred in seven patients $(11.7 \%)$, and premenstrual pain was experienced for the first time by four $(6.7 \%)$. There were no cases of mood changes arising following the change to the lower dose preparation. Three women developed headaches while four noticed diminution of headache. In addition, two women had increased vaginal bleeding, and one developed jaundice of uncertain origin.
This pattern of side effects is quite different from that described by Dr. Grant, and is probably due to the fact that in our series the ratio of oestrogen to progestogen remained the same in the two preparations. Dr. Grant discusses five quite different lowoestrogen formulations, and, as she points out, side effects vary widely according to the relative progestogenicity of the oral contraceptive. We would, therefore, like to suggest that the effects noted in our study reflect more accurately an absolute reduction in the amount of steroid administered. whereas Dr. Grant's figures represent a variety of oestrogen/progestogen combinations.

Furthermore, the "symptom" of reduced vaginal bleeding is, on the whole, welcomed by patients; only when it amounts to complete absence of bleeding does it give cause for concern to both patient and prescriber. In this latter respect it is reassuring to note that of the eight pseudoamenorrhoeic patients in our study four have resumed regular bleeding while continuing to take Ortho-Novin $1 / 50$ and one further patient who had no withdrawal bleeding on Ortho-Novin $2 \mathrm{mg}$. resumed bleeding when changed to the lower dose preparation. There remain the symptoms of break-through bleeding and premenstrual pain; in neither case did any patient find that the side effects were sufficient to stop taking oral contraceptives.-We are, etc.,

S. M. WOOD.

J. A. McEwan.

\section{Family Planning Clinic. Guy's Hospital.}

\section{Reaction to Iron Sorbitol Injection}

SIR,-We agree with the suggestion of Dr. P. Karhunen and others (30 May, p. 521) that there is need for further study on the toxic effects of free iron in patients with malabsorption syndrome. Despite the reputed low incidence of anaphylactic reactions following total dose infusion therapy using high molecular weight iron-dextran (Imferon) we reported ${ }^{1}$ a 59-year-old man with gluten sensitive steatorrhea who had a non-fatal anaphylactic reaction following 15 drops of an intravenous solution given over $90 \mathrm{sec}$. and containing $25 \mathrm{ml}$. iron dextran in $500 \mathrm{ml}$. of $5 \%$ dextrose and water. An E.C.G. done immediately before and within 10 minutes after the reaction did not show any arrythmias.

Because of the small volume administered and the speed of onset of the reaction we do not feel that increased susceptibility to the toxic effects of iron was the cause. We feel that the likely explanation was on an allergic basis and that steatorrhea, like asthma and other allergic conditions, should be considered a contraindication to total dose infusion iron therapy.-We are, etc.,

M. Soots.

G. D. Hart

\section{Department of Haematology, \\ oronto East General Hospital Toronto 13. Ontario. Canada.}

REFERENCF Hart, G. D., and Soots, M., Applied Thera-
peutics, 1969, 11, 645. 